\title{
A survey of adoption of endodontic nickel-titanium rotary instrumentation part 2: community and hospital dental practitioners in Wales
}

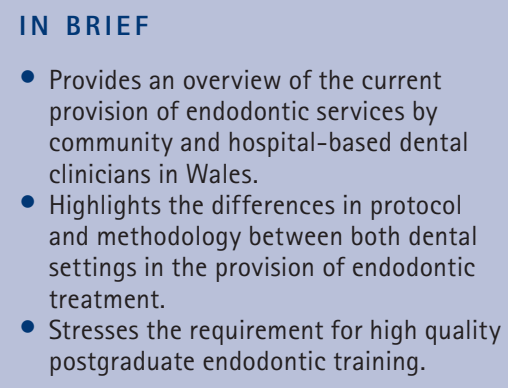

\author{
M. B. Thomas, ${ }^{1}$ M. Locke ${ }^{* 2}$ and P. M. H. Dummer ${ }^{3}$
}

Objectives To assess adoption of endodontic nickel-titanium rotary technology (NiTi) by community and hospital dental clinicians within Wales and identify factors that may restrict uptake. Design Postal questionnaire. Setting Community and hospital-based dentists in Wales. Methods Community and hospital-based dentists with a remit for provision of restorative dentistry (community dental setting $=32$; hospital dental setting $=36$ ) were approached regarding their usage or otherwise of nickel-titanium rotary instrumentation for endodontic treatments. The postal questionnaire took the form of an anonymous survey comprising 12 questions. These questions covered usage parameters, satisfaction and training and broached reasons for NiTi avoidance. Results The response rate was 77\%. NiTi rotary instruments were used routinely by an encouraging $82 \%$ of those in the hospital-based restorative dental services but only $13 \%$ of community staff. Factors cited as being implicated in the decision to avoid their use included cost (62\% of responses) lack of training and the perceived lack of benefit. Conclusion The adoption of rotary NiTi endodontic technology by the hospital dental practitioners of Wales is encouraging with the majority having converted to such systems in excess of three years prior to the survey. There was, however, a significant disparity in NiTi usage between community and hospital settings, the implications for which and possible solutions for increased training and uptake are discussed.

\section{INTRODUCTION}

In part one of this survey ${ }^{1}$ it was found that a significant number (67\%) of general dental practitioners (GDPs) working within private and NHS contracts within Wales had converted to and were utilising rotary nickel titanium (NiTi) technologies during their endodontic practice.

Data was also captured for those dental staff employed within either the community dental settings (CDS) or hospitalbased restorative dental services (HDS). Although geographical boundaries within Wales are small, and certainly the numbers of dental community and hospital centres are minimal, there exists little cross-Wales data on how staff are trained in and undertake endodontic treatments. It is known

\footnotetext{
Specialist Registrar in Restorative Dentistry, ${ }^{2}$ Clinical Lecturer, Tissue Engineering and Reparative Dentistry, ${ }^{3}$ Professor of Restorative Dentistry, Cardiff University School of Dentistry, Heath Park, Cardiff, CF14 4XY

${ }^{*}$ Correspondence to: Dr Matthew Locke

Email: lockem1@cardiff.ac.uk;

Telephone: 02920743504
}

Online article number E7

Refereed Paper - accepted 31 October 2012

DOI: 10.1038/sj.bdj.2013.109

${ }^{\circ}$ British Dental Journal 2013; 214: E7 that within Wales (with only one teaching dental institution) NiTi is the taught standard and has been since 1998 .

Within the UK the dental NHS remuneration system, time-pressures, increasing patient expectations and inadequate technical equipment have all been expressed by GDPs as having bearing on treatment quality. ${ }^{2}$ Little has been written with regards to training and financial arrangements for staff linked with CDS and HDS settings and the uptake of NiTi by those involved in secondary care institutions has rarely been measured.

The use of nickel-titanium alloys for endodontic instruments has expanded since the developments reported by Walia et $a l .^{3}$ Nickel titanium alloys allow for simplification of endodontic procedures and increased efficiency. Thompson and Dummer et al. ${ }^{4}$ have previously described the shaping ability of different NiTi systems and there has been demonstration of nickel-titanium superiority over conventional instruments, not only in their ability to provide appropriate tapered funnel shape to the root canal (curved or straight) but in their ability to produce less preparation aberrations such as zips, ledges and perforations. ${ }^{5-9}$

The aim of the present study was to (i) investigate the rate of adoption of $\mathrm{NiTi}$ endodontic instrumentation among the National cohort of Dentists working within CDS and HDS settings within Wales and (ii) determine the factors associated with uptake or avoidance of such technologies.

\section{METHODS}

Methods were described in part one of this study. ${ }^{1}$ Briefly, In October 2010 a prepiloted postal questionnaire was delivered to all CDS and HDS departments in Wales using an address database held by the Welsh Dental Postgraduate Department.

The questionnaire began with an introductory explanation as to its purpose and emphasised its anonymity. Due to such anonymity a repeat sending of the questionnaire was not possible. A post-reply envelope was included.

After a three month reply period, data was collated and examined.

\section{RESULTS}

The results are given as absolute frequencies 
as well as percentages. The response rate was $77 \%$ ( $\mathrm{n}=52$ returns of 68 questionnaires), an encouraging response and similar when compared to other dental postal questionnaires. ${ }^{10}$ One HDS responder chose to opt out of answering the questionnaire. This left 51 appropriately answered questionnaires (74\%) with which to proceed to data analysis.

\section{Question 1}

Dentists were asked whether they considered root canal treatment services to be in their remit. This is relevant for those dentists working within the CDS or HDS where specific job planning may preclude the provision of any endodontic treatments. It was of note that just four responses from the HDS (11\%) and two from the CDS (6\%) were to the negative.

\section{Question 2}

This related to NHS or private contract type and was aimed solely at the general dental practitioner arm of the study.

\section{Question 3}

This questioned asked approximately how many root canal treatments were carried out on a weekly basis. Categories comprised 1-5, 6-10 or 10+ (Fig. 1).

It was apparent that very similar numbers of treatments were performed weekly with HDS and CDS staff, the majority performing between one and five treatments weekly. When data was grouped very few HDS staff $(5 \%, n=4)$ were performing in excess of five treatments and none of those from the CDS.

\section{Question 4}

This examined the numbers of dentists that used (for the overwhelming majority of cases) nickel-titanium rotary instrumentation (Fig. 2). Results were polarised, $\mathrm{CDH}$ staff demonstrating 13\% uptake with NiTi and HDS staff $82 \%$.

The data for those not undertaking use of NiTi was then utilised in question five, the remaining responses used in questions numbered six through nine.

\section{Question 5}

Those practitioners not routinely using NiTi were then asked to provide reasons as to why this is the case. Pre-defined scenarios with check boxes were drawn

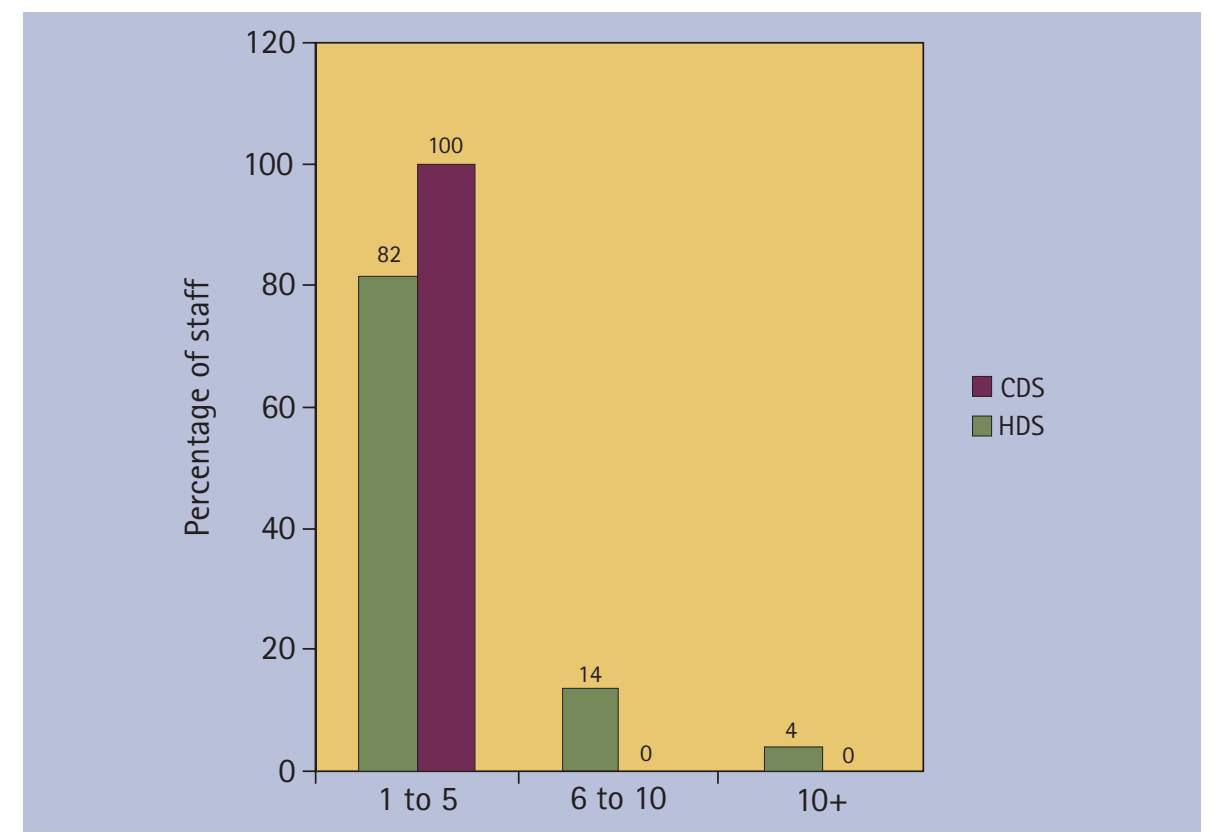

Fig. 1 Numbers of endodontic treatments performed weekly

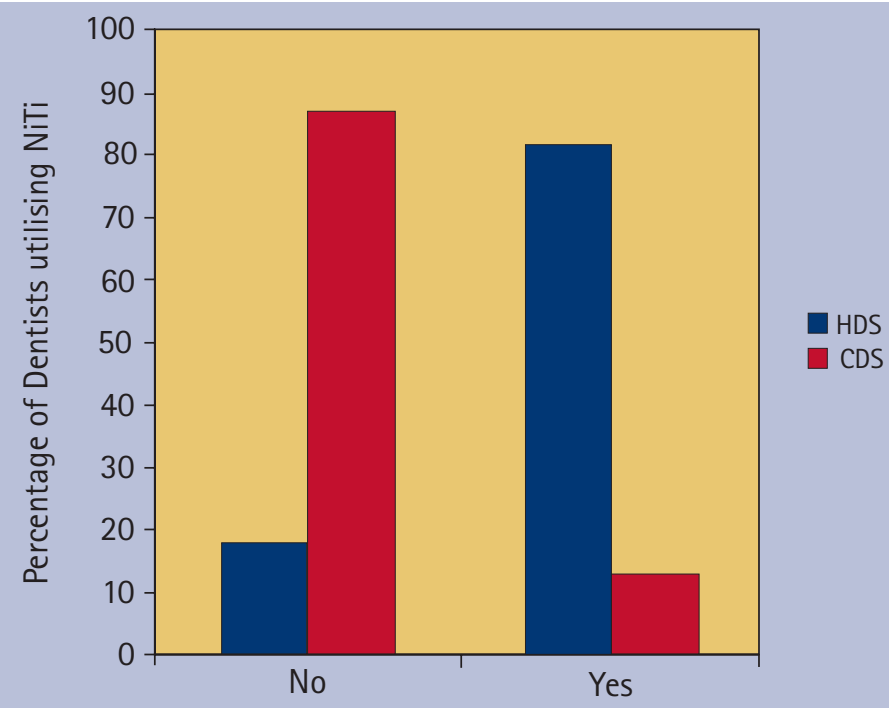

Fig. 2 Numbers of HDS/CDS staff utilising NiTi

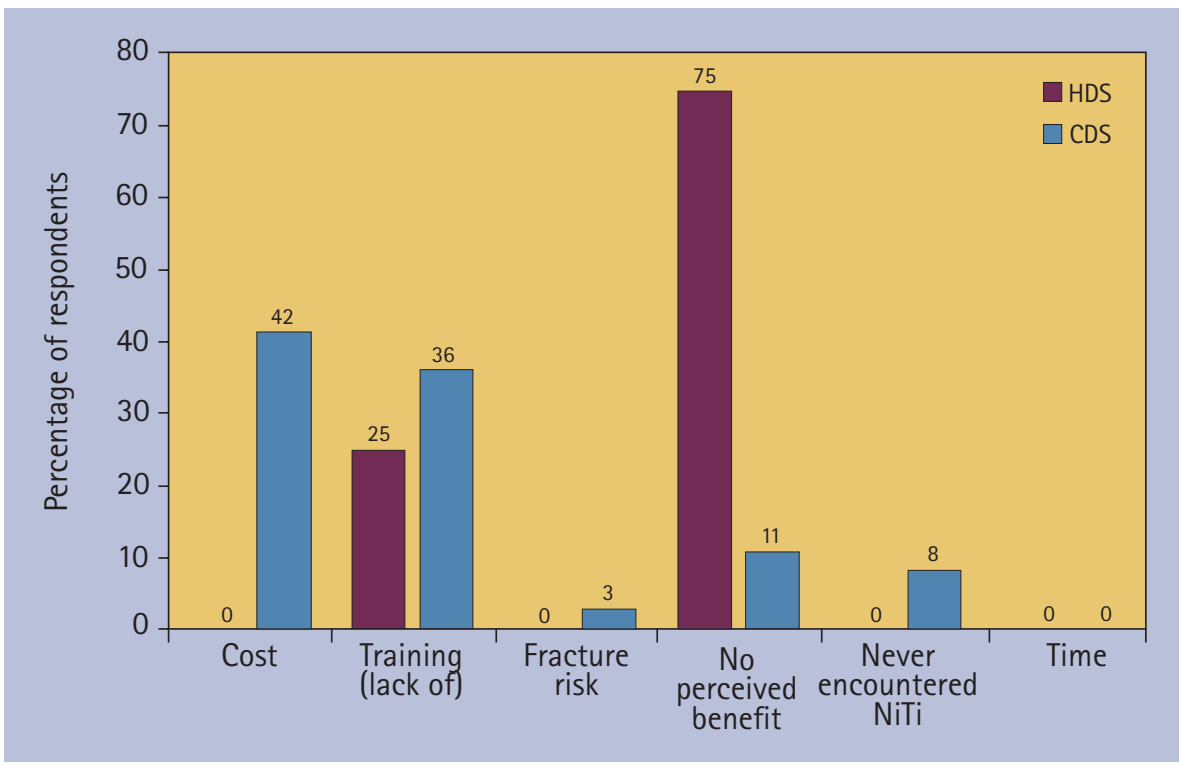

Fig. 3 Factors inhibiting uptake of NiTi technology 
up with the option to comment further if applicable. Multiple answers were allowed (Fig. 3).

It is to be appreciated here that only four HDS members responded as not utilising NiTi, one (25\%) of whom cited lack of training the other three (75\%) citing no perceived benefit. This was in stark contrast with the CDS staff where of the 20 respondents $42 \%$ stated that cost was the inhibitory factor, 36\% lack of training, $11 \%$ perceived no benefit and $8 \%$ had never encountered NiTi.

\section{Question 6}

Returning to the cohort of responders that were utilising NiTi, question six enquired as to how many years such systems had been in use. Check boxes were included for 'less than 1 year', '1-3 years', '4-6 years' and ' $7+$ years'. The majority of dentists $(90 \%, \mathrm{n}=19)$ had been doing so for in excess of seven years.

\section{Question 7}

Responses were sought for the NiTi system manufacturer utilised. Multiple answers were accepted and eight popular systems provided as pre-designed answers. The option was provided for alternate systems. Only ProTaper ${ }^{\circledR}$ and Profile ${ }^{\circledR}$ systems were utilised, with ProTaper ${ }^{\circledR}$ holding the majority at $86 \%(n=18)$.

\section{Question 8}

Question eight attempted to ascertain whether practitioners utilised NiTi-based hand-files either, instead of, or as a supplement to the rotary system. A significant majority $(81 \%, \mathrm{n}=17)$ did use NiTi hand files.

\section{Question 9}

It was asked whether dentists had either an interest in endodontics or perhaps a specific postgraduate qualification. Seventyone percent $(n=15)$ of responders did express such an interest.

\section{Question 10}

It was asked whether respondents had partaken in any form of postgraduate training in nickel-titanium rotary instrument usage. It is useful to delineate CDS and HDS responses; with HDS all but one respondent (95\%) had undertaken training, whereas for CDS only $61 \%$ had.

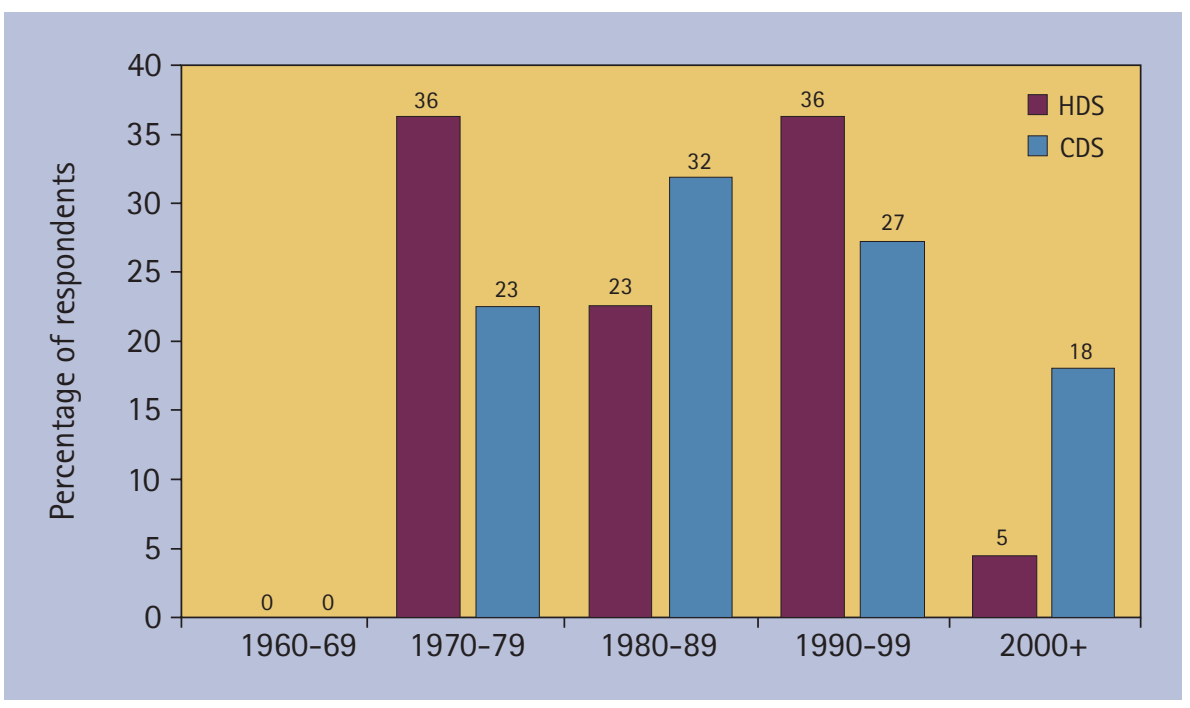

Fig. 4 Year of qualification

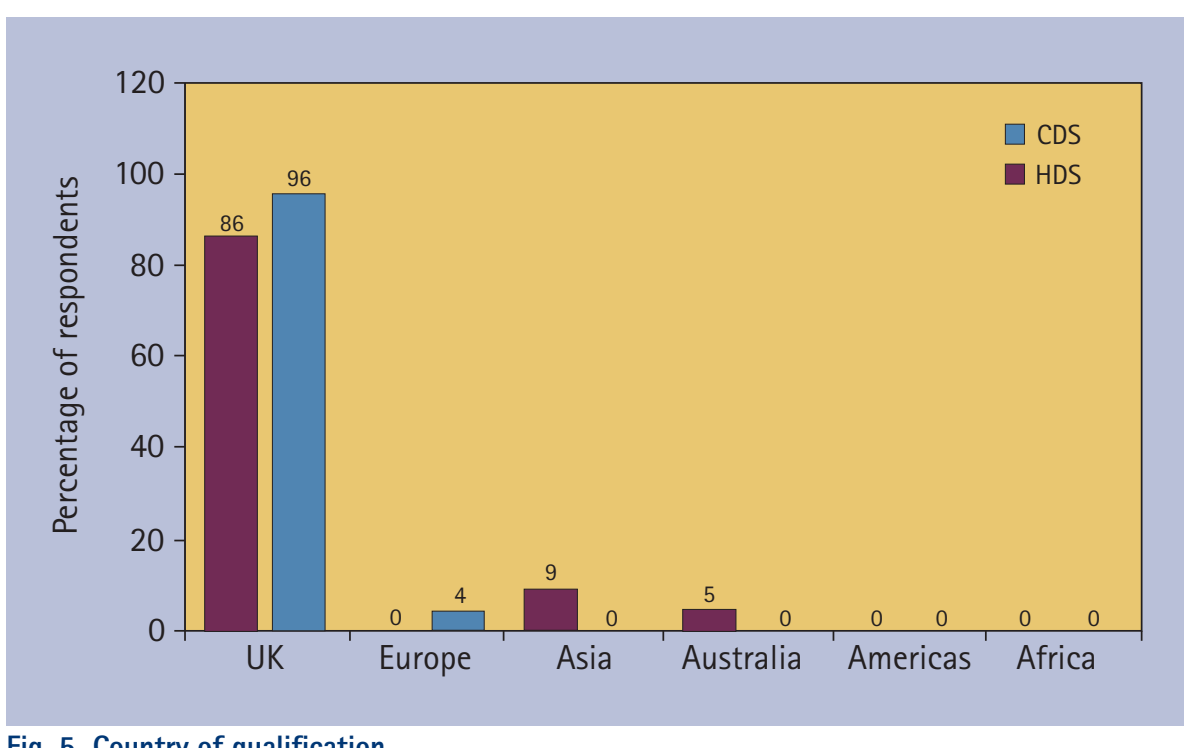

Fig. 5 Country of qualification

\section{Question 11}

Further, it was enquired whether postgraduate training in the use of nickel-titanium endodontic instrumentation would be beneficial to the practitioners of Wales. A combined total of $85 \%(n=34)$ thought that this would be of benefit ( $91 \%$ of CDS respondents alone).

\section{Question 12}

The remaining two questions were of demographics. Question 12 was used to determine the year of qualification (Fig. 4).

\section{Question 13}

This enquired as to country of qualification. In line with historical data the overwhelming majority $(91 \%, \mathrm{n}=41$ [combined data]) were of 'UK and Ireland' origin with few from mainland Europe, Asia and Africa (Fig 5).

\section{DISCUSSION}

This project sought to collect data from dentists working within restorative dentistry departments of hospitals or community dental clinics in Wales. A postal survey provided a simple means of data collection, in this survey the response rate was a satisfactory (77\%), a repeat mailing being impossible because of anonymity. It is accepted that interpretation of survey data must take into account the possibility of participant bias.

Within the discussion inferences have been made relating to the person specification, job planning and remit that relate to the two differing dental environments.

Wales has a unique position in the UK with one dental teaching hospital and school located at its capital, Cardiff. It is fortunate that data on community dental settings and teaching and/or district 
general hospitals is held centrally within the Postgraduate Department of Medical and Dental Education. This has allowed the authors an ideal opportunity to investigate, as a whole, the endodontic practising methods of the nation's dentists.

\section{NiTi advantages}

The advantages of NiTi have been reviewed in part one of this study ${ }^{1}$ and emphasised the enhanced shaping, simplicity and timesaving effects of using NiTi technology. Although improved clinical outcomes with the use of rotary instruments is still not a conclusive finding within the endodontic literature, there is evidence to suggest rotary instrumentation provides several advantages over previous hand-filing techniques, in particular its efficiency. ${ }^{11}$

\section{Data on NiTi uptake}

It is appropriate to separate the data for hospital versus community dental practice due to the wide variability in some answers. The most obvious being that $82 \%$ of hospital-based dentists were utilising NiTi versus just 13\% by their CDS counterparts. This is a clear difference in clinical protocol between the two dental settings and raises several questions. Clearly endodontics does play a part in CDS remit and it is apparent from the year of qualification data that there are likely many recently qualified practitioners who by inference would be conversant with NiTi technology from their undergraduate training. Indeed, in Wales there is a strong cohort of recently qualified (and hence NiTifamiliar) dental foundation trainees that rotate through CDS clinics as part of their early post-qualification training.

\section{Barriers to uptake}

The majority response from the CDS pertaining to lack of NiTi use was that of 'cost'. There is a clear difference between CDS and HDS environments with regard to budget allocation and spend. Dental hospital environments are particularly fortunate to have allocated funds for clinical treatments and endodontic instruments included, thus cost of materials is perhaps not of 'direct' concern, a scenario that the authors suggest is not mirrored in the CDS.

Thirty-six percent of CDS staff that cited 'lack of training' as an inhibitory factor is enlightening and the $8 \%$ that had "never encountered NiTi' of further interest. These figures being almost twice that found for the survey of GDPs. It would seem apparent that the level of postgraduate training and operator experience with NiTi within the CDS is less than the GDP (and HDS) cohort. This may offer solutions for increased NiTi usage by providing high quality postgraduate education in order to encourage a move toward this technology.

\section{Undergraduate NiTi education}

It is not known exactly how many UK dental schools advocate the use of NiTi but is likely an increasing majority. Nearer the inception of NiTi a postal survey by Qualtrough et al. ${ }^{12}$ found that in 1999 NiTi was still in its infancy in all except the North American, Scandinavian, and Western European schools. Later ArbabChirani and Vulcain ${ }^{13}$ found that $81 \%$ of French universities were teaching rotary instrumentation during pre-clinical and clinical education. More recently still Sonntag et al. ${ }^{14}$ demonstrated that $63 \%$ of German dental schools taught root canal preparation with rotary nickel titanium instruments. There would seem to be an increasing body of evidence to suggest that dental students achieve significantly better results in root canal preparation with rotary instruments than with stainless steel hand instruments alone. ${ }^{15-17}$ Despite this, and as alluded to in part one, ${ }^{1}$ Parashos and Messer ${ }^{18}$ have shown that despite the fact that new materials and techniques may have a beneficial influence on the outcome of treatment their uptake is a slow process.

For introduction of newer technologies into dentistry it may be best to consider uptake at the undergraduate level. A recent paper by Friedlander and Anderson ${ }^{19}$ has emphasised that the teaching of 'advanced endodontic courses at the undergraduate level is common even though it can be difficult to assess teaching effectiveness'. If introduced at the undergraduate level the notion of lifelong learning can be better instilled. In the case of the dental teaching institution of Wales NiTi technology has been incorporated into the curriculum for many years. This may be of little benefit to practitioners who graduated before the advent of NiTi but an emphasis on correct and contemporary technical teachings (along with appropriate continuing professional development) is paramount if practitioners are to achieve the most efficient outcomes for their clinical treatments.

\section{Postgraduate NiTi training}

It has been suggested that without a good understanding of anatomy and pathology mechanical instrumentation will not improve endodontic outcome. ${ }^{20}$ The successful introduction of new technologies into routine clinical practice would appear to require not only effective products, but also the appropriate data and educational underpinnings to underscore their usefulness to practitioners. ${ }^{21}$ In a study of 702 UK-based primary dental care practitioners Palmer et al. ${ }^{22}$ found that almost $25 \%$ of respondents had not received any teaching or training in endodontics in the past two years. A study of Swedish dentists Reit et al..$^{23}$ found significantly more individuals willing to adopt a rotary endodontic system when hands-on training was included in the educational package, as compared with lectures and written information alone. In mirroring the findings of Reit et al. ${ }^{23}$ the adoption of a new technology might be influenced by the design of an introductory educational programme.

Supervised and focused continuing education improves clinical skills and knowledge and helps delay declining clinical competence. Adoption rates as high as $80 \%$ are reported for GDPs who had attended courses in the NiTi rotary technique, including hands-on training. . $^{232}$ Uptake has been suggested to be strongly linked with practical experience and training. ${ }^{25}$ This certainly agrees with the paper's findings in that a significant number of dentists have agreed that postgraduate courses would be of benefit.

Successful continuing education programs should include individualised feedback, face-to-face assistance, objective setting and the use of opinion leaders as role models. Courses should be providing information as a means of reducing uncertainty about an innovation and focusing on how to control and direct the innovation. Educators must recognise that different people have different aptitudes and different skill levels. ${ }^{18}$ For clinical procedures, such as root canal instrumentation, the inclusion of hands-on training sessions would seem to be important to reach a high acceptance rate. Such courses may also be effective in both providing students 
with the basic skills for using this type of instrumentation and increasing their understanding and enthusiasm for endodontics. ${ }^{19}$ There is scant data on the longterm effects of postgraduate clinical skills training, however, Dahlström et al. ${ }^{26}$ has shown, via a cohort of Swedish General Practitioners, that good root filling quality obtained after attendance of an endodontic education package was maintained some four years later.

\section{CONCLUSIONS}

Rotary NiTi endodontic technology has had an excellent level of uptake within the cohort of HDS staff of Wales but worryingly low in the CDS setting.

The NHS remuneration system within the CDS appears to have a negative influence on the rate of adoption of NiTi instrumentation.

Although increased success rates with the use of rotary instrumentation is still not a conclusive finding within the endodontic literature, there is evidence to suggest such instrumentation provides several advantages over traditional handfiling techniques, in particular the speed and efficiency of canal preparation. High quality hands-on practical postgraduate courses may be of benefit in allowing dentists in all settings introductory experience, thereby easing the transfer to newer technologies. A dissemination of the practising regimes of HDS staff to their CDS colleagues may ease the transition to NiTi technology.
Certainly there exist, and will remain, financial barriers relating to NiTi uptake for those dentists practising within CDS settings in comparison with HDS institutions.

1. Locke M, Thomas M B, Dummer, P M H. A survey of adoption of endodontic nickel-titanium rotary instrumentation part 1: general dental practitioners in Wales. Br Dent J 2013: 214: E6.

2. McColl E, Smith M, Whitworth J, Seccombe G, Steele J. Barriers to improving endodontic care: the views of NHS practitioners. Br Dent J 1999: 186: 564-568.

3. Walia H M, Brantley W A, Gerstein H. An initial investigation of the bending and torsional properties of Nitinol root canal files. J Endod 1988; 14: 346-351.

4. Thompson S A, Dummer P M. Shaping ability of ProFile.04 Taper Series 29 rotary nickel-titanium instruments in simulated root canals. Part 1. Int Endod J 1997; 30: 1-7.

5. Bishop K Dummer P M. A comparison of stainless steel Flexofiles and nickel-titanium NiTiFlex files during the shaping of simulated canals. Int Endod $J$ 1997; 30: 25-34.

6. Thompson S A, Dummer P M. Shaping ability of ProFile.04 Taper Series 29 rotary nickel-titanium instruments in simulated root canals. Part 2. Int Endod J 1997: 30: 8-15.

7. Park H. A comparison of Greater Taper files, ProFiles, and stainless steel files to shape curved root canals. Oral Surg Oral Med Oral Pathol Oral Radiol Endo 2001: 91: 715-718.

8. Schäfer $E$, Lohmann D. Efficiency of rotary nicke titanium FlexMaster instruments compared with stainless steel hand K-Flexofile - part 2. Cleaning effectiveness and instrumentation results in severely curved root canals of extracted teeth. Int Endod J 2002: 35: 514-521.

9. Schäfer E, Schulz-Bongert U, Tulus G. Palmer N 0 . Comparison of hand stainless steel and nickel titanium rotary instrumentation: a clinical study. J Endod 2004; 30: 432-435

10. Tan R T, Burke FJ. Response rates to questionnaires mailed to dentists: a review of 77 publications. Int Dent J 1997: 47: 349-354.

11. Baumann M A, Roth A. Effect of experience on quality of canal preparation with rotary nickeltitanium files. Oral Surg Oral Med Oral Pathol Oral Radiol Endod 1999; 88: 714-718.

12. Qualtrough A J, Whitworth J M, Dummer P M. Preclinical endodontology: an international comparison. Int Endod J 1999; 32: 406-414.
13. Arbab-Chirani R, Vulcain J M. Undergraduate teaching and clinical use of rotary nickel-titanium endodontic instruments: a survey of French dental schools. Int Endod J 2004; 37: 320-324.

14. Sonntag D, Bärwald R, Hülsmann M, Stachniss V. Pre-clinical endodontics: a survey among German dental schools. Int Endod J 2008; 41: 863-868.

15. Namazikhah M S, Mokhlis H R, Alasmakh K. Comparison between a hand stainless-steel $\mathrm{K}$ file and a rotary NiTi 0.04 taper. J Calif Dent Assoc 2000; 28: 421-426.

16. Garip Y, Günday M. The use of computed tomography when comparing nickel-titanium and stainless steel files during preparation of simulated curved canals. Int Endod J 2001; 34: 452-457.

17. Gluskin A H, Brown D C, Buchanan L S. A reconstructed computerized tomographic comparison of $\mathrm{Ni}$-Ti rotary GT files versus traditional instruments in canals shaped by novice operators. Int Endod J 2001; 34: 476-484.

18. Parashos $\mathrm{P}$, Messer $\mathrm{H} \mathrm{H}$. The diffusion of innovation in dentistry: a review using rotary nickel-titanium technology as an example. Oral Surg Oral Med Oral Pathol Oral Radiol Endod 2006; 101: 395-401.

19. Friedlander $L$, Anderson V. A new predoctoral endodontic module: evaluating learning and effectiveness. J Dent Educ 2011; 75: 351-359.

20. Spångberg L. The wonderful world of rotary root canal preparation. Oral Surg Oral Med Oral Pathol Oral Radiol Endod 2001; 92: 479

21. Barnett M L. Decisions, decisions: challenges to the introduction of new technologies to clinical practice. J Dent Res 2002; 81: 5 .

22. Palmer N O, Ahmed M, Grieveson B. An investigation of current endodontic practice and training needs in primary care in the north west of England. Br Dent J 2009; 206: E22.

23. Reit C, Bergenholtz G, Caplan D, Molander A. The effect of educational intervention on the adoption of nickel-titanium rotary instrumentation in a Public Dental Service. Int Endod J 2007; 40: 268-274

24. Barbakow F, Lutz F. The 'Lightspeed' preparation technique evaluated by Swiss clinicians after attending continuing education courses. Int Endod J 1997; 30: 46-50.

25. Koch $M$, Eriksson H G, Axelsson S, Tegelberg A Effect of educational intervention on adoption of new endodontic technology by general dental practitioners: a questionnaire survey. Int Endod J 2009; 42: 313-321.

26. Dahlström L, Molander A, Reit C. Introducing nickeltitanium rotary instrumentation in a public dental service: the long-term effect on root filling quality. Oral Surg Oral Med Oral Pathol Oral Radiol Endod 2011; 112: 814-819. 